\title{
Mujeres, finanzas sociales y violencia
}

\author{
Cristina Palomar Verea
}

El libro titulado Mujeres, finanzas sociales y violencia económica en zonas marginadas de Guadalajara, de la doctora Magdalena Villarreal y editado en colaboración por el Instituto Jalisciense de las Mujeres y el Instituto Municipal de las Mujeres en Guadalajara, es uno de los frutos del esfuerzo que estas instituciones han realizado en los últimos años por acercar la academia a la promoción de los derechos humanos de las mujeres. Labor loable, ya que las tareas de editar y difundir trabajos de investigación de calidad muestran no solamente la voluntad de estos organismos por trabajar por las mujeres de Jalisco, sino también por promover el avance del conocimiento de sus realidades y de su diversidad.

De esta labor es fruto el libro que se reseña: se trata del resultado de un trabajo de investigación serio y minucioso realizado en Guadalajara en el 2008, que responde a la preocupación por conocer las condiciones de las mujeres que viven en la precariedad económica, buscando explicar los nexos entre pobreza, género y violencia, a través del conocimiento de sus prácticas financieras.

Profesora investigadora del CUCSH, Universidad de Guadalajara. El estudio se llevó a cabo en cuatro colonias de la ciudad caracterizadas por la pobreza: Lomas del Paraíso, Pueblo Quieto, El Embarcadero y La Comunidad Mixteca. Si bien cada una

Magdalena Villarreal Martínez (2009), Mujeres, finanzas sociales y violencia económica en zonas marginadas de Guadalajara, Guadalajara, México, Instituto Jalisciense de las Mujeres e Instituto Municipal de las Mujeres en Guadalajara, 172 pp. 
de estas colonias presenta rasgos y aspectos distintos para el tema de análisis, el foco de atención se centró, en todos los casos, en las mujeres que viven ahí y en sus prácticas cotidianas para lidiar con sus necesidades de sobrevivencia en un contexto de precariedad económica.

A través de una estrategia de investigación concienzuda y extensa, y con un equipo de investigadores jóvenes y creativos, Magda Villarreal condujo la investigación por vías originales para producir con sus resultados un texto que ofrece a sus lectores una perspectiva novedosa y refrescante acerca de un sector de la población que suele pensarse a partir de prejuicios y de falsas ideas, responsables de la creencia de que es imposible transformar las cosas.

A pesar de que el título del libro parece anunciar un texto árido y difícil, éste es, por el contrario, un texto ameno y bien escrito que, desde el principio, engancha en la lectura al mostrar, con una fluida narración, a los sujetos de investigación en su dimensión más humana y cotidiana, sin por eso dejar de analizar el complejo contexto en el que realizan sus prácticas financieras. De esta manera Licha, Tomasa, Chepa o Conchita se vuelven personajes reales y cercanos, a quienes dan ganas de acompañar para entender cómo, viviendo en condiciones tan difíciles, manejan sus recursos, hacen sus cálculos y navegan con sus deudas, para salir adelante.

Después de un capítulo inicial que presenta una descripción elocuente del universo de estudio, del procedimiento metodológico y de los sujetos de la investigación, el texto se organiza en cuatro apartados: 1. Los ingresos, arreglos, responsabilidades y dependencias; 2. Los dispendios, identidades y administración de la carencia; 3 . La organización de las finanzas, y 4 . La violencia económica. Al final se incluye un último capítulo en el que se habla de los recursos de los pobres y el manejo de finanzas en la búsqueda de alternativas, y con el que queda claro que este tema está lleno de 
matices y contradicciones, que hacen evidente que la economía no se puede reducir a una cuestión de pesos y centavos, y que la erradicación de la pobreza implica mucho más que la producción, el consumo y los servicios financieros.

Lo primero que hay que decir es que este reporte de investigación es un texto que deberían leer los alumnos de las licenciaturas en ciencias sociales, ya que muestra, de manera casi didáctica, lo que es una buena investigación social que combina métodos cualitativos y cuantitativos, que discute conceptos e ideas fundamentales para el tema de las finanzas sociales, y cuyo diseño del trabajo de campo incluye distintos procedimientos y técnicas - trabajo etnográfico, aplicación de encuestas, realización de entrevistas- que produjeron una gran cantidad de datos que, posteriormente, es analizado de una manera inteligente y documentada. Pero no solamente por eso vale la pena leer este texto; también es un excelente ejemplo del enfoque más acertado para estudiar los temas de las mujeres que viven en el contexto de la pobreza, librando los lugares comunes y las afirmaciones prefabricadas que se encuentran con frecuencia.

Este libro nos revela que estudiar el tema del manejo de las finanzas de las mujeres marginadas revela algunas de las trampas y de los malentendidos que suelen estar involucrados en las maneras en que, de manera simplista, se interpretan la desigualdad, la pobreza y las inequidades. $\mathrm{Al}$ cuestionar y rebatir prejuicios y categorías fijadas de antemano con las que a veces se pretenden explicar dichos fenómenos, Magda Villarreal nos muestra, de manera imbatible, una realidad distinta de aquélla que suele dibujarse cuando se separa tajantemente a los pobres de los ricos, a los hombres de las mujeres, a los indígenas de "los otros", a los normales de los anormales o excluidos. La perspectiva original de esta investigación devela, por el contrario, un mundo lleno de matices y claroscuros que nos dan una visión 
extraordinariamente rica de un mundo que, solamente desde su desconocimiento, se imagina de un solo plano.

Por otra parte, en la lectura de este libro se hace evidente que aquello que suele llamarse "lo económico" implica diversos circuitos que componen, en conjunto, el amplio tejido vital de los actores sociales. De esta manera, "lo económico" - se revela en este texto-, desborda con mucho el tema del dinero, comprendiendo otras áreas de la existencia que son también sujetas de cálculos y maniobras, tales como la búsqueda para asegurarse un lugar en el grupo social, para agenciarse los apoyos de las redes sociales, para lidiar con los conflictos. Todo esto son recursos que no hay que menospreciar, ya que forman parte de la sobrevivencia social, la cual es igual de importante que la mera sobrevivencia.

Vista desde este ángulo, la investigación de Magda Villarreal y su equipo muestra que las mujeres clasificadas como "pobres" están comprometidas en una lucha existencial mucho más amplia y compleja que lo que representa estrictamente "talonear la chuleta". Se trata de una lucha con muchas implicaciones, ya que se vincula con cuestiones identitarias tales como la etnicidad, el género o la pertenencia a una comunidad, y que se manifiesta, en las existencias concretas de las mujeres entrevistadas, plena de recursos y de capacidades. Es decir, la idea de los sujetos de la pobreza como sujetos carentes y vulnerables es contradicha en este trabajo: estas mujeres, aunque reconocen sus condiciones, no están situadas en una posición de postración o de pasividad, sino que dan señales de una vitalidad y un ingenio francamente reconfortantes.

El trabajo describe, además, de manera muy clara, que la pobreza es una condición que se produce discursivamente para otros; la carencia es algo que es percibido y enunciado más bien "desde fuera". Es el otro — el diferente, el extraño, el ajeno- quien carece; y no porque sea patente "la falta" que padece, sino porque, en tanto el que enuncia se sitúa

\section{6}


en el lugar de "quien es", el otro ocupa, necesariamente, el lugar del que "no es". No obstante, habría que darle vueltas a una pregunta que surge espontáneamente en la lectura de este libro: ¿por qué parece que a las mujeres "les viene bien" situarse en el lugar de la carencia, ser el pobre entre los pobres?

Ni la pobreza ni el lugar de víctima son consustanciales a ninguna clase de sujeto. Este trabajo evidencia claramente que son las categorías que clasifican socialmente a los sujetos y su asignación diferencial, lo que produce ese efecto imaginario. A través de la investigación queda claro que ser categorizada como mujer, como pobre y/o como indígena (por los otros y por una misma) es el principal obstáculo para librar los efectos perniciosos del género, de la pobreza y del racismo.

Ahora bien: si bien es el discurso lo que construye la discriminación y las diferencias, son los sujetos quienes las encarnan y las actúan. Pero también quienes los contradicen y los retan: la existencia de estas mujeres sobrevivientes y activas son la prueba de ello. De esta reflexión es de donde la autora extrae lo que es, probablemente, la tesis central del texto: la violencia más sutil hacia las mujeres es conceptualizarlas como víctimas sin capacidad de actuar sobre su realidad para transformarla según sus intereses y cálculos. Es violencia porque, en verdad, las hace víctimas.

Por otra parte, el texto nos dice que la flexibilidad es una característica notable en las mujeres estudiadas en la investigación, lo cual se evidencia en distintas situaciones y nos hace pensar en lo que algunos estudiosos/as han observado en relación con el desigual proceso de transformación de las identidades de género a través del tiempo: las mujeres, en tanto sector que tiene poco que perder, ha improvisado formas creativas para sustraerse al constreñimiento del género, mientras que los varones — que no tienen una necesidad tan punzante para transformar el orden de género-, 
se han rigidizado en los estereotipos y las tareas que se les han asignado, y se aferran a las posiciones tradicionales. En este estudio se muestra abundantemente que son las mujeres quienes, con flexibilidad y empeño, con responsabilidad y compromiso, enfrentan las necesidades de la sobrevivencia cotidiana, y no los imaginarios "varones proveedores".

En síntesis, creo que este trabajo llama la atención sobre ciertos elementos que contribuyen al fracaso de las usuales iniciativas para hacer frente a la pobreza, particularmente en lo que se refiere a interpretaciones sobre los recursos de las mujeres en sectores marginales y su manejo de las finanzas. El libro de Magda Villarreal es un excelente texto que no solamente puede aportar elementos para colaborar con las propuestas de combate a la pobreza, sino que abre los ojos al lector para mirar de una manera distinta a las mujeres, situándolas como actoras que, si bien lidian con una existencia difícil, son también capaces de enfrentar su situación con ingenio y con otros recursos importantes que les sirven para tejer vínculos y redes sociales fundamentales para la convivencia de todos, lo cual representa un considerable capital social. Pero no por esto el libro es una exaltación irresponsable y romántica de estas mujeres, ya que también propone una perspectiva crítica que permite advertir los mecanismos de complicidad, colaboración y participación en el orden social (económico y de género) que muchas veces impide la transformación de las opresiones implicadas en su subordinación, y que es en donde reside probablemente la peor trampa para la transformación del mundo social. 8 